\section{ELECTRIC DISCHARGE IN GASES ${ }^{1}$} II.

THE form of point most favourable to the production of the arc has been minutely investigated by the authors. By turning wires in a lathe to various outlines they arrived experimentally at the best point; this was then placed under the microscope and drawn by means of the camera lucida; from the study of the drawing it was ascertained that the longest spark was procured when the point assumed a form resembling a paraboloid; the curved out

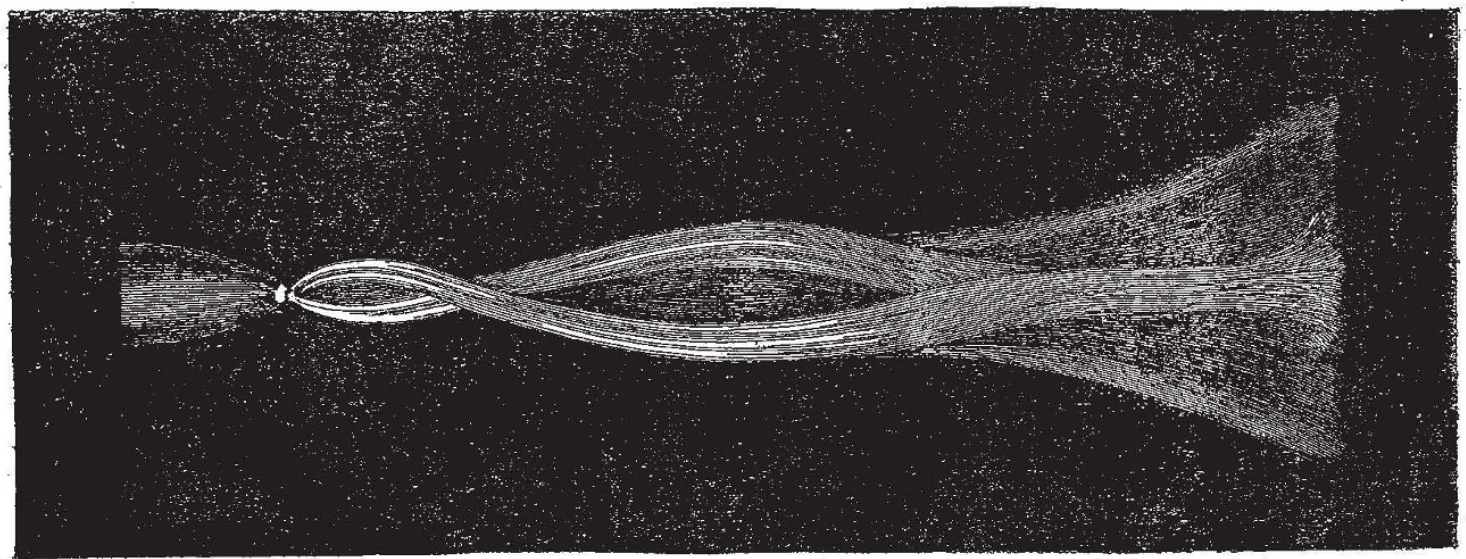

Fic. 8.- "Streamers."

line, which corresponded to that found experimentally, was one in which each succeeding ordinate was in the ratio of the square root of the odd numbers $\mathrm{I}, 3,5$, \&c., the sectional areas being consequently in the ratio of the odd numbers.

The curves in the diagram (p. 528) show the distances at which, with a given potential, the arc is formed between such a pointand a disc, and between two such points respectively. The results recorded in the case of the point and disc are those obtained by electrifying the point to the sign (positive or negative) which gave the greatest length; for it was found that with low potentials the distance at

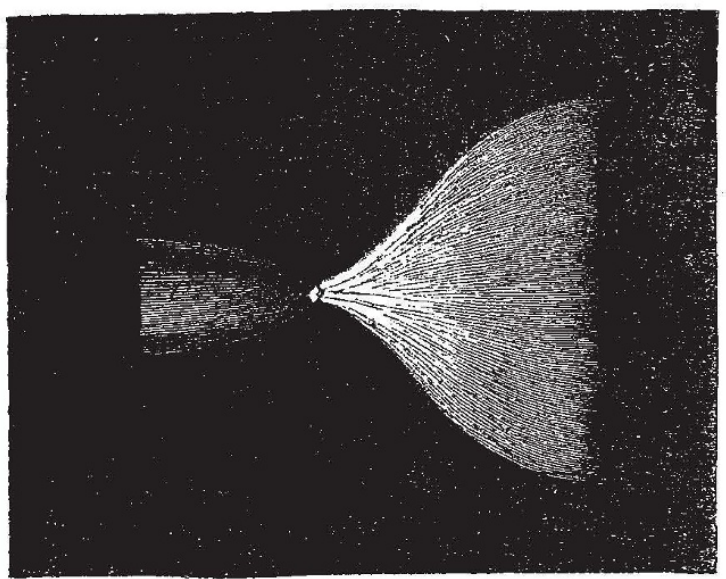

FIG. 9-“G:ow."

which the arc forms is greater when the point is negative, that between 3,000 and 5,000 volts it is the same whether the point be positive or negative, but that with potentials higher than 5,000 volts it is greater when the point is positive.

The actual formation of the arc, when a point and disc or two points are employed as terminals, is preceded by a luminous discharge (streamers and glow), presenting pbenomena of an interesting character; an extremely

x Continued from f. 528 . minute quantity of electricity passes as compared to that

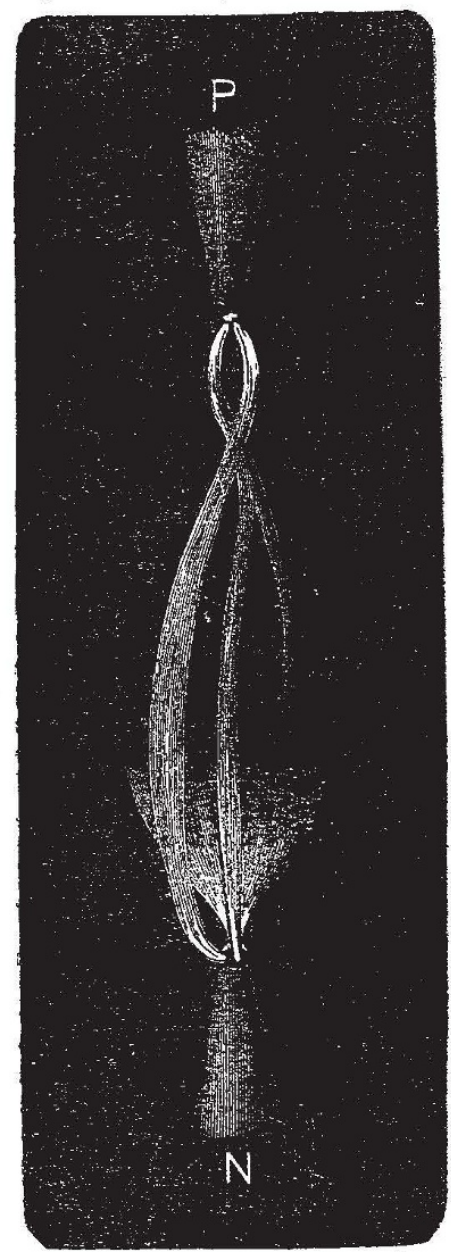

Fli. xu. - "itriners and Glowo".

when the arc is formed, but still it is su ficient when 
caused to pass through a vacuum tube to illuminate it strongly.

"The discharge from the point, when positive, has mainly to the naked eye a stream-like appearance, consisting of a waving line of light surrounded by a very faint sugar-loaf luminosity, and producing a rattling or strong hissing sound; from the point when negative it consists of a glow of light paraboloidal in form, and extending from the point to the disc, but much more brilliant at the point, the noise of the discharge being much less than when the point is positive. The disc, especially when positive, soon becomes covered with a peach-like bloom, and the deposit assumes the appearance of Newton's rings.

"Small as this current is, it is, nevertheless, very manifest from its brightness and the rattling, or loud hissing noise it produces; it frequently continues for some minutes before the spark actually jumps between terminals placed at the striking distance asunder; the streamerdischarge becomes brighter just before the jump and formation of the arc, and this suggested the possibility of particles being carried off in increasing quantity from the point to the disc, and thus contributing to the production of the spark. In order to test this hypothesis, the terminals were placed at the striking distance, and a con- tinuous blast from a blowpipe bellows sent between them; this did not, however, have any effect on the length of the spark, but it deflected the arc when once it had formed.

"Under the microscope the discharge, from the point when positive, is seen to consist of several streams of light, which twist round each other like loosely-bound strands, as shown in Fig. 8, representing the discharge between the terminals, a point and a disc, in a horizontal discharger. Part of the discharge from the point negative is shown in Fig. 9. Fig. 10 shows on a scale of 4 to I the phenomenon obtained with 11,000 cells, the streamers and glow proceeding simultaneously from the opposite points of a vertical discharger and existing independently of each other."

In order to study these discharges the authors constructed a microscope (Fig. II) with a revolving mirror placed at an angle formed by the two tubes composing the body of the microscope, which is bent for the convenience of observation. That part beyond the upright is formed of ebonite, in order to protect the eye from accidental shocks. The discharger used when this microscope was employed was horizontal, as seen in the figure, in order to permit of the employment of the mirror which was mounted on a horizontal axis; the

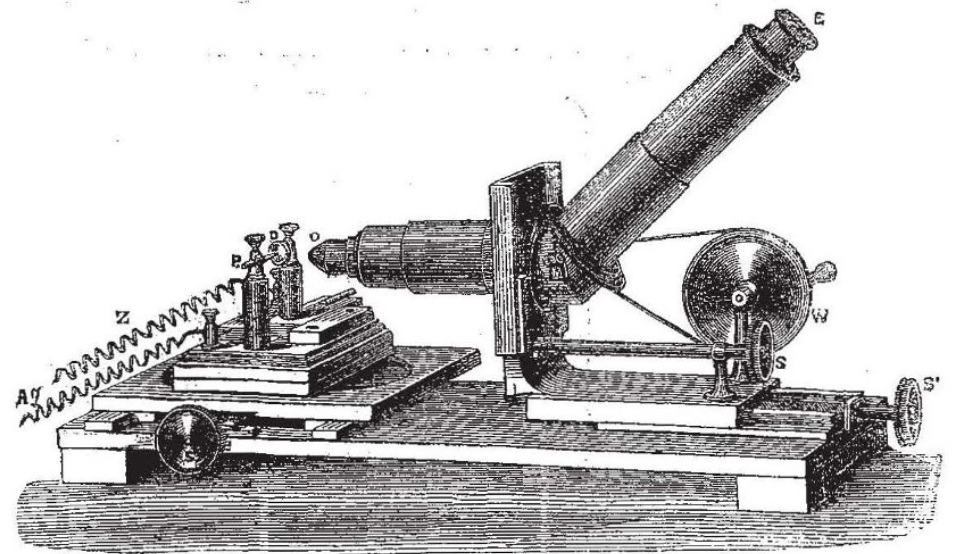

FIG. II,-Microscope with Revolving Mirrur.

point $P$ was placed in the fixed upright, and the disc $D$ in that upright which is attached to the adjustable slide. The screw $S^{\prime}$ is used to approach or recede the microscope in order to adjust to focus; $\mathrm{s}^{\prime \prime}$ to bring the point horizontally, and $\mathrm{s}$ to elevate or depress the microscope by means of a pinion and rack to adjust the point vertically in the field. $O$ is the object-glass and $\mathrm{E}$ the eyepiece; $w$ a multiplying-wheel giving five revolutions of the mirror for one turn of the handle, which may be rotated with ease 200 times in a minute, so that the mirror can be caused to make 1,000 revolutions in a minute, or about seventeen revolutions in a second. The whole framework of the stand is of ebonite, to ensure insulation.

"When the revolving mirror was set in motion it was seen that the streamer-discharge was in reality, to a great extent, intermittent. At times a moderate rotationvelocity of the mirror served to show this by the production of a number of distinct images, as seen in the lefthand drawing in Fig. I2; at others it required the full speed of the mirror. The discharge appeared much more continuous with the point negative: so much so that the image was generally seen in the microscope as a sheet of light brightest near the point, and nearly uniform in a direction at right angles to the axis of the mirror. The right-hand drawing shows the appearance when the point is negative. The difference in the sound emitted when the point is positive and negative respec-

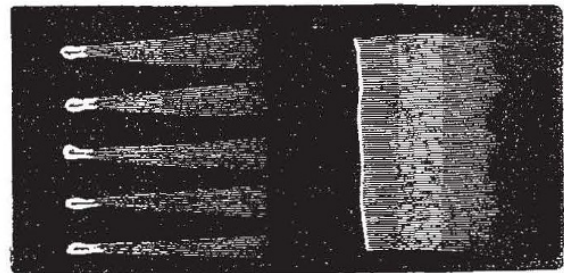

FIG. 13.-Analysis of Streamers and Glow.

tively appears to afford an additional proof of less continuity in the case of the positive.

"When a high resistance-four megohms, for example -was inserted in the circuit, the character of the discharge was completely changed. Instead of jumping across and forming an arc, a series of brilliant snapping sparks pass between the terminals at more or less rapid intervals, exactly like the sparks from a small Leyden jar; these pierce a piece of writing paper interposed between the terminals, producing minute holes. The spark does not jump at the full distance when the four megohms resistance is inserted; and, to produce an almost continuous succession of intermittent sparks, it was usually necessary to approach the point to $0^{\prime} 30$ inch, when, without resistance, the spark with 8,040 cells would jump and form the arc at $0^{\prime} 34$ inch."

When charcoal terminals were used the jump of the spark was about the same as with other terminals having a similar shape; the charcoal points could be separated when 8,040 cells were used to $x^{\circ} 25$ inch generally, and occasionally to $I$ ' 5 inch, without breaking the arc. The arc presented the ordinary characters, as shown in Fig. I3; but that which takes place when the terminals are vertically one over the other is different, on account of its being undisturbed by upward air currents which deflect the arc.

The length of the spark differs in various gases at ordinary atmospheric pressures, but the authors found 
that the difference in the length of the spark does not bear any precise ratio either to the specific: gravity of the gas or its viscosity in reference to mechanical impulse; they propose to ascribe it, at all events provisionally, to a difference of electric viscosity. In order to make experiments on the dge ischarin different gases, they placed the

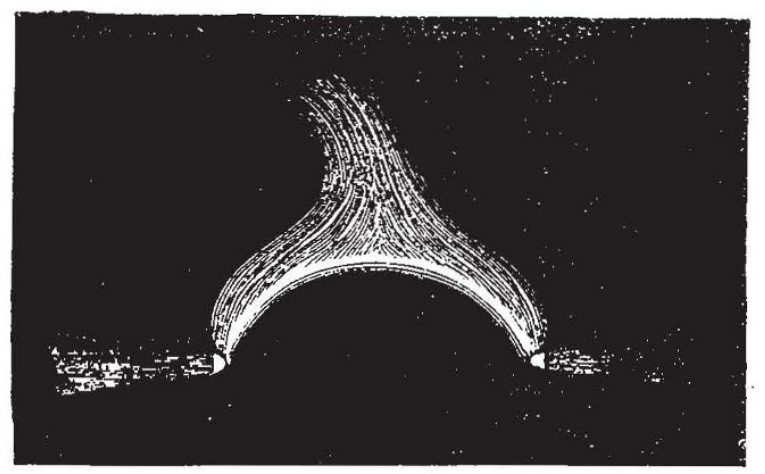

Fic. 13.-Arc Letween Charc:al Poin:s.

discharger already described (Fig. 4), under a bell glass (: (:' (Fig. I4) open at the top and covered with a glass plate $P$. The glass plate had two screw-clamps which were connected at its under surface with wires led from the screw clamps $c$ and $c^{\prime}$ of the discharger. In connection with thesc, on the outside surface, were two other screw-

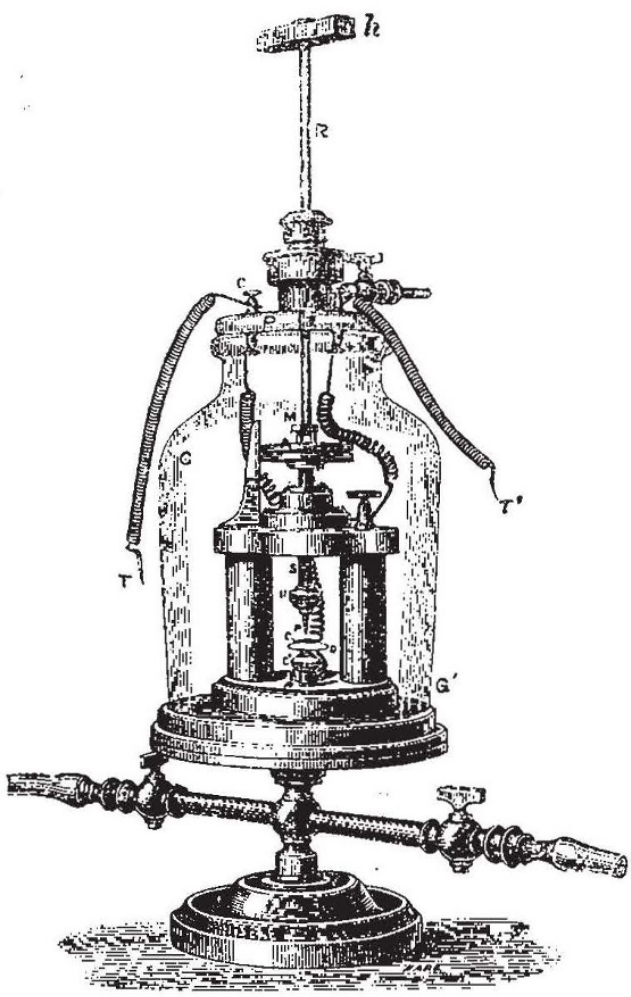

II 1 , 14,-Apparatus for Measuring Length of $S_{i j a r k}$ in Different Gases or at Different Fressures.

clamp: $c c^{\prime}$ with which the terminals of the battery $\mathrm{T} \mathrm{T}^{\prime}$ were connected. Through a stuffing box in the glass cover a steel rod $\mathrm{R}$ passed; this, below the glass, carried a crutch $\mathrm{M}$, with two cbonite pins, which drop into corresponding holes made to receive them in the micrometer wheel A; the rod had on the top, outside the jar, a cross handle $\hbar$ for turning it. The distance of the tcrminals was easily regulated by means of this rod, as the micrometer could be read through the bell glass. Before admitting any gas into it, the bell glass was exhausted by the mercurial pump to a pressure of less than a millimetre, then filled with dry gas, and again exhausted and recharged. The following table shows the result:s obtained with spherical surfaces $I^{\prime} 5$ inch in diameter and 3 inclies radius.

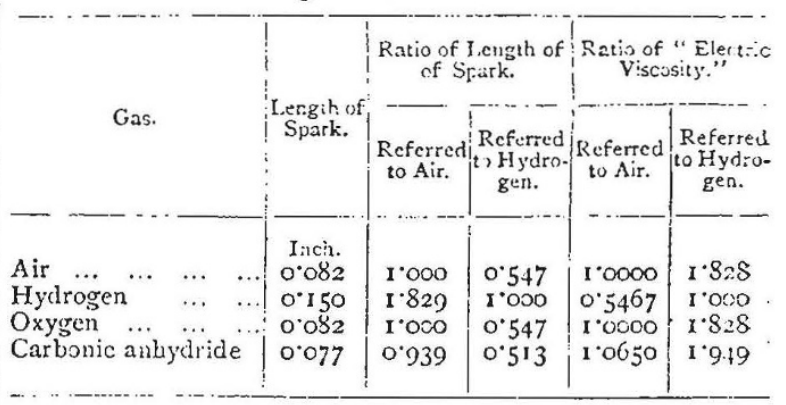

The appearance of the arc was different in different gases, as will be seen in Fig. 15, where I represents the arc in air; this when examined with the nicroscope pre-
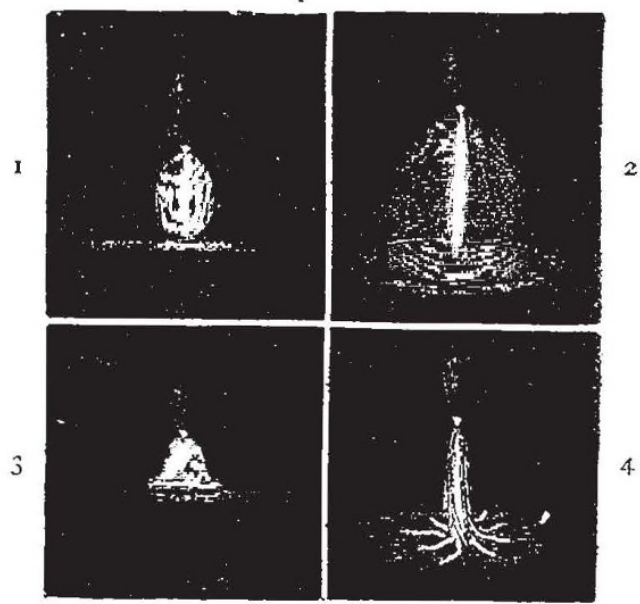

F 15. 15.-The Arc in Different Gases.

sented an evidently stratified appearance, especially in the barrel-shaped surrounding of the central bright spindle; the laminæ were extremely close and seen with very great difficulty, even with the revolving mirror of the microscope; with a moderate magnifier, a hand lens, the barrel-shaped surrounding appeared as if shaded with lines across it.

The arc in hydrogen, with the point positive, is shown in 2 , Fig. 15 ; the central spindle was surrounded by a beautifui blue ha!o like a glass shade illumined by fluorescent light, and very brilliant on the disc. Witb four megohms resistance in the circuit, the streaming discharge from the point positive, at 0.502 inch distance, was carmine in colour. This distinctive colour is a proof that the gas in which the discharge takes place is the carrier of electrification in the streamer discharge. The appearance of the arc when the point is negative is shown in 4 , Fig. 15 ; it moved about very rapidly and formed a starlike appearance on the positive disc; when the point was negative, before the jump of the spark, a very pale glassshade-like halo, of a saddened olive tint extended from the point almost to the outer periphery of the disc.

The arc in nitrogen was reddish violet, and in oxygen it presented an appearance similar to that in air. Tbe arc in carbonic anhydride is shown in $3, \mathrm{Firg}$. 15. 
In the course of their experiments several curious and interesting phenomena were noticed incidentally. A slip of dry glazed note paper, when placed upon the disc of the discharger (Fig. 4), the other terminal being a point, was attracted to the disc so as to require a lateral pull amounting, in some cases, to as much as 30,000 grains, to cause it to slide over the disc: this lateral strain was reproduced when the paper was pressed against the disc by a weight of 129,690 grains. We must refer our readers to the original memoir itself for the full discussion of this phenomenon.

When the terminals were placed opposite to two gas

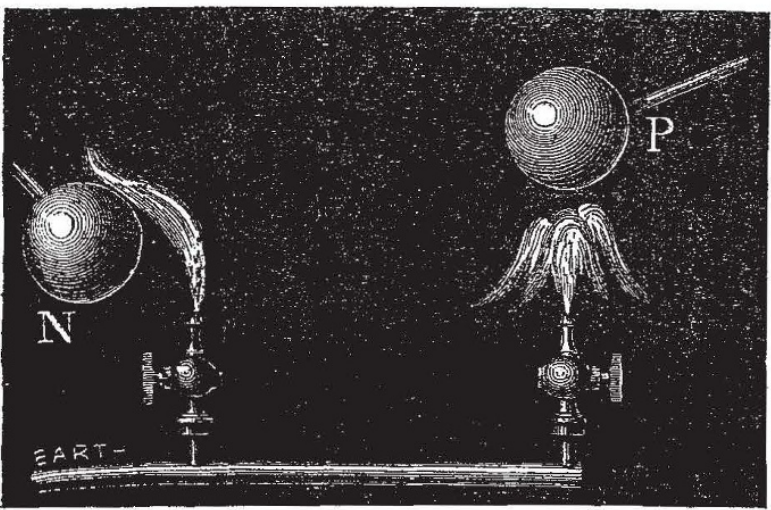

Fig. 16.-Repul.ivn of Gas-flame.

jets emanating from the same gas pipe in metallic communication with the gas main, and consequently to earth, the flame opposed to the negative terminal is attracted, but that opposed to the positive repelled, as was observed to be the case with static electricity by M. Neyreneuf, at whose request the experiment was made. Fig. I 6 shows the arrangement and effects observed.

"When one of the terminals consisted of a very fine platinum wire 0.002 inch diameter and about 0.56 inch long, held in a holder like that used for holding needles in a mathematical instrument box, but adapted to go into the discharger, the wire took up a straight, circular, or elliptical oscillation, the glow at the point forming a continuous line of light marking its course; with the point positive the excursion was less than when negative, being with a potential of 8,040 cells, and a distance between the terminals of 0.32 inch, about 0.375 inch; with the point negative it was much more brilliant and about 0.8 inch. By interposing a resistance of 4 megohms the statical discharge took place from the extremity of the wire, frequently producing a beautiful and brilliant figure by the apparent crossing and interlacing of the bright lines of discharge from different points in the path of the oscillating wire; these occurred at such short intervals that the discharge looked like a persistent pattern of intricate engine-turning. By approaching the wire cautiously it was generally possible to cause the end of it to fuse into a minute globule, and the discharge then became much more striking. With 4 megohms resistance the static spark was longest and brightest when the wire was negative; if the wire was very straight, the oscillations took place in a cycloidal curve in a vertical plane, the discharge occurring at equal distances from the middle of the path as the minute globule at the end of the wire attained the limit of the greatest discharge from either side, so that two streaks of light were seen continuously; if the wire was slightly bent, the oscillation was conical or elliptical, and the figure produced by the discharge was then much more continuous and beautiful, because the distance from the point to the plate remained nearly constant."

Another point studied by the authors was the deflagration of wires of different metals. With their condenser of 42.8 microfarads charged with 3,240 cells, they could deflagrate 10.5 inches of platinum wire 0.0125 inch in diameter. When $2 \frac{1}{2}$ inches of either platinum, gold, silver, copper, iron, zinc, or aluminium wire of this size, strained across and kept in close contact with a piece of plate glass perforated with two holes to admit of screw clamps to press the ends of the wire tightly against it, is deflagrated by the above charge, the wire is dispersed with a' strong explosion, like that of a pistol, the metal being driven into and strongly adhering to the glass for some distance from the wire. The greatest dispersion is towards the middle of the wire, and all along the path of the discharge is crossed by furrows in which the metal is deposited. This appearance suggested the idea of a stress at right angles

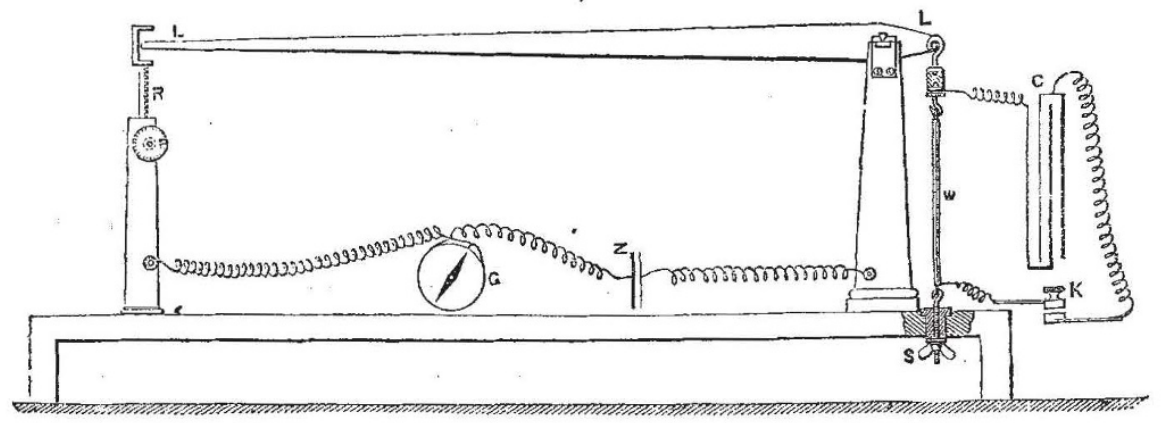

Fig. 17.

to the path of the discharge which might involve a notable longitudinal contraction.

An experiment was made to test this hypothesis, but the results were entirely negative. When the key $\mathrm{K}$ (Fig. 17) was pressed down the accumulator $\mathrm{C}$ was discharged through the wire $w$, which was 8 inches long, and of diameters varying from $0^{\circ} 2$ to 0.0125 inch; if now the wire had, at the moment of discharge, contracted longitudinally by $\frac{1}{1}=0$ inch, the fact would have been recorded by the deflection of the galvanometer G, in consequence of the closing of the circuit of the battery $z$, at the extremity of the long arm of the lever; with this apparatus, ho:rever, the contraction, if it occurred, was not detected; the extremity of the lever was not observed to rise before it descended in consequence of the elevated temperature of $w$; after $w$ had been allowed to cool down to its original temperature, the extremity of the lever remained slightly below its original position.

Only a few experiments have as yet been made by the authors on the length of spark at different pressures below that of the atmosphere, but they intend to pursue this investigation with a micrometer discharger of longer range than that shown in Fig. 4.

With two spherical surfaces, each of 3 inches radius of 
curvature and $\mathrm{I}_{5} 5$ inch diameter, the following results were obtained with 8,040 cells :-

\begin{tabular}{|c|c|c|c|c|}
\hline Pressure. & $\left\{\begin{array}{c}\text { Fraction of an } \\
\text { atmosphere. }\end{array}\right.$ & $\begin{array}{l}\text { Length of } \\
\text { spark. }\end{array}$ & $\begin{array}{l}\text { Ratio to } \\
\text { length at I } \\
\text { atmosphere. }\end{array}$ & $\begin{array}{l}\text { Ratio of length of } \\
\text { spark to dilatation }\end{array}$ \\
\hline $\begin{array}{l}\text { Millims. } \\
760\end{array}$ & 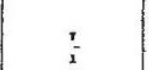 & $\begin{array}{l}\text { Inch. } \\
\text { 0.079 }\end{array}$ & 1.00 & $\frac{x}{x}=r^{\prime} \cdot 000$ \\
\hline $6 \odot 2$ & & 0.100 & $1 \cdot 26$ & $\frac{x^{2}}{x^{2} 262}=0^{\prime} .999$ \\
\hline $4^{1} 4^{\circ} 7$ & $\frac{x}{x \cdot 833}$ & 0.200 & $2 \cdot 52$ & $\frac{2^{\prime} 5^{2}}{x^{\prime} 833}=1^{*} 375$ \\
\hline $299^{\circ} 5$ & $\frac{x}{2537}$ & 0.400 & $5^{*} \times 4$ & $\frac{504}{2.537}=1.986$ \\
\hline$I_{4} I \cdot 5$ & $\frac{x}{5370}$ & 0.800 & 10.08 & $\frac{7008}{5.370}=I .876$ \\
\hline
\end{tabular}

\section{ERNEST QUETELET}

THE death of M. Ernest Quetelet, "chef du service Astronomique " of the Observatory of Brussels, took place at Ixelles on the 6th instant, after a long and painful illness. His connection with the observatory dates from 1855, when he entered it as an assistant to his father, the late Lambert Adolphe Jacques Quetelet, who was then the director, and who died so recently as February, 1874. Ernest was born in Brussels August 7, 1825. At that time his father was busily occupied in pressing on the king and the municipality of Brussels the importance of establishing an observatory for meteorological purposes. After much discussion and many delays it was determined in 1826 to establish an astronomical observatory; Quetelet was directed to obtain instruments, to visit Paris and London, and on January 9, I 828 , he received his official appointment, his title being "astronomer." The three principal astronomical instruments were set up in 1835 , but the first four volumes of the Annales of the observatory coming down to 1845 contain only meteorological notes. The first rolume (date 1834) opens with an "aperçu historique des observations de météorologie faites en Belgique jusqu'à ce jour," commencing with 1763, and shows how thoroughly the director entered into the importance of the work. The observatory in 1845 was the centre of meteorological observing stations, of which there were more than eighty.

Although Ernest, as he grew up, shared his father's interest in the various observations included under the head meteorological, and took terrestrial magnetism as a special subject for study, on joining the observatory in I 855 he was appointed to take the astronomical observa tions and the Annales record that the observations were made by him and the calculations of the reductions by M. L. Estourgies. From 1857 he has had in liand the revision of a catalogue of the variable stars, a large part of which has been published. Two years ago he issued the climatological elements of Brussels, in a series of eighteen tables, for the ten years ending 1873 , and in the Bulletin of the Societé Royale are many papers by him on magnetism.

Before entering the observatory he was in the Engineers for several years, after having passed through the École Militaire of Brussels. In 1848 he was engaged as a subaltern on the work of the fortifications of Antwerp. It was while still in the Engineers he communicated his first paper to the Academy, "Recherches sur les Médianes" (October 9, 1859), which was printed in the Mémoirs Couronnés. In 1856 , shortly after joining the Observatory, he wrote a paper on the magnetism of the earth in North Germany and Holland, and in 1859, "On the Magnetic Declination at Brussels."

The Observatory has all through its existence had to struggle against difficulties; one of the latest recommendations of the Commission on it was to effect the following improvements :-
"To complete the magnetic system of the Observatory by the acquisition of self-registering instruments, to organise the International Meteorological Service, to obtain an equatorial of large dimensions with the accessories necessary to the spectroscopic investigation of the heavens, and to increase the number and improve the position of the observer."

During many years M. Quetelet has often been appointed referee to the printing of papers in the Mémoires of the Académie Royale, and has been himself a frequent contributor.

\section{GEOGRAPHICAL NOTES}

IN the Geographical Section of the French Association some papers of interest were read. Dr. Carret read a curious paper on the Distribution of Antipodes, in which the author indulged in some rather fanciful theorising. Gen. Ricci spoke on the geodetic work carried on by the Italian Government, which is energetically completing the triangulation of Italy, connecting it with the rest of Europe on the one side and Africa on the other. Gen. Ricci also spoke of the regular tidal observations carried on at various stations on the coast of Italy, mainly with a view of getting a true level for geodetic purposes. M. H. Duveyrier read an elaborate paper on the remaining problems in African geography, in which he divided unknown Africa into seven great regions: (1) The Sahara and the Libyan Desert; (2) The country between the Joliba and the Guinea Coast; (3) The upper courses of the Binue and Shari; (4) The region behind Cape Guardafui ; (5) The equatorial chain of lofty mountains ; (6) The completion of the basins of the Nile, Congo, and Ogove; (7) The basin of the Cunene. Altogether more than $\mathrm{I}, \infty \infty, 000$ square kilometres remain unexplored, more than one-third of the whole surface of Africa. At the mean rate of discovery since the beginning of the century, this might be covered in about forty-eight years, though the ratio is now so increased that it ought to be done in much less time. A paper by $M$. Maunoir recounted the services done to geography by France since 1800 , and when all put together with the eloquence of a Frenchman, they seem formidable.

News from Capt. 'Tyson's Arctic expedition in the Florence has been brought to Washington by the schooner Helen, which wintered in the same bay on the coast of Cumberland. Meteorological observations were taken most accurately during winter by Mr. Sherman, the physicist of the expedition. Unfortunately the natu-. ralist inflicted on himself a wound when on duty, and was disabled for the greater part of the winter. Capt. Tyson went to Disco to recruit natives, collect goods, and purchase dogs. He fulfilled his duty with his wonted activity and success. But when everything was ready he learned by a message sent from Washington that the preparations were useless, the American Congress having taken its vacation without deliberating upon the report so carefully drawn by the Marine Committee. The brave and accomplished commander of the Florence is now on his way to Washington, where he is expected daily. We are informed that a demonstration will be made against this piece of Parliamentary negligence. This preliminary expedition was entirely fitted out at the expense of Capt. Howgate and his friends.

NEwS has arrived that the Bremen steamer Neptune, Capt. Rasmussen, which left for the $\mathrm{Ob}$, in Siberia, on July $x 6$, reached Hammerfest on the 6th instant with a full cargo of Siberian wheat. The Neptune was laden with all sorts of mercantile goods. She entered the Nadym on August 13 , and had no ice difficulties on the voyage out. "Perhaps in future, when the 